\title{
Penerapan Data Mining Apriori Pada Persediaan Obat (Studi Kasus Apotek Rafif Farma Medan)
}

\author{
Mardiah \\ Universitas Nahdlatul Ulama Sumatera Utara, Medan, Indonesia \\ Email : mardiahindin23@gmail.com
}

\begin{abstract}
Abstrak
Pentingnya sistem persediaan barang di suatu Apotek dan jenis barang mana yang menjadi prioritas utama yang harus di stok. Hal tersebut berguna untuk mengantisipasi kekosongan barang. Karena minimnya stok barang dapat berpengaruh pada pelayanan konsumen dan asset bagi Apotek. Oleh karena itu, penelitian ini dilakukan untuk membantu menyelesaikan permasalahan tersebut dengan merancang sebuah aplikasi Data Mining yang berfungsi untuk memprediksi penjualan obat terbanyak dapat diketahui, diperlukan Algoritma Apriori dengan bantuan Tools Tanagra. Salah satu tahap analisis asosiasi yang menarik yaitu menghasilkan algoritma analisis pola frequensi tinggi (frequent pattern mining).
\end{abstract}

Kata Kunci: Data Mining, Algoritma Apriori, Association Rule

\section{Abstract}

The importance of inventory systems at a pharmacy and the type of goods which are a top priority that must be in stock. It is useful to anticipate the void stuff. Due to the lack of inventory may affect customer service and asset to the pharmacy. Therefore, this study was conducted to help resolve those problems by designing a data mining application that serves to predict sales of the drug is needed most knowable a priori algorithm with the help of Tools Tanagra. One of the interesting association analysis phase analysis algorithm that generates a high frequency patterns (frequent pattern mining).

Keywords: Data Mining, Apriori Algorithm, Association Rule 


\section{Pendahuluan}

Algoritma Apriori termasuk jenis aturan asosiasi pada Data Mining, Algoritma Apriori yang bertujuan untuk menemukan frequentitemsets dijalankan pada sekumpulan data. Analisis Apriori didefenisikan suatu proses untuk menemukan semua aturan Apriori yang memenuhi syarat minimum untuk support dan syarat minimum untuk confidence.

Penelitian yang ingin dicapai adalah :

1. Mengimplementasikan Data Mining pada database transaksi penjualan item obat-obatan

2. Membentuk pola kombinasi itemsets dari data penjualan (data obat keluar) dengan menggunakan Algoritma Apriori.

3. Menghasilkan rules dengan associationrules dari pola kombinasi itemsets yang interesting.

\section{Kajian Literatur Dan Pengembangan Hipotesis}

\subsection{Knowledge Discovery in Databases (KDD)}

Discovery adalah proses pencarian dalam basis data untuk menemukan pola yang tersembunyi tanpa ide yang didapatkan sebelumnya atau hipotesa tentang pola yang ada. Dengan kata lain aplikasi mengambil inisiatif untuk menemukan pola dalam data tanpa pengguna berpikir mengenai pertanyaan yang relevan terlebih dulu (Eka Novita Sari, 2013).

\section{2 Data Mining}

Data Mining adalah metode untuk mencari data terlaris atau paling banyak di butuhkan customer. Data Mining merupakan analisis data menggunakan tool untuk menemukan pola dan aturan dalam himpunan data. Perangkat lunak bertugas untuk menemukan pola dengan mengidentifikasi aturan dan fitur pada data dan diharapkan mampu mengenal pola ini dalam data dengan input minimal dari user. Salah satu bentuk pola yang dapat dihasilkan Data Mining adalah Association Rule.

\subsection{Association Rule}

Aturan asosiasi akan menggunakan data latihan, sesuai dengan pengertian Data Mining, untuk menghasilkan pengetahuan. Pengetahuan untuk mengetahui item-item belanja yang sering dibeli secara bersamaan dalam suatu waktu. Aturan asosiasi yang berbentuk "if...then..." atau "jika...maka..." merupakan pengetahuan yang dihasilkan dari fungsi aturan asosiasi (Kennedi Tampubolon, et al, 2013).

\subsection{Algoritma Apriori}

Algoritma Apriori adalah adalah Algoritma yang paling terkenal untuk menemukan pola Frekuensi tinggi. Algoritma Apriori dibagi menjadi beberapa tahap. yang disebut narasi atau pass (Devi dinda setiawan, 2009).

\section{Metodologi Penelitian}

Pada metode penelitian yang digunakan adalah metode apriori dengan pendekatan terstuktur (Structured Approach) yang lengkap dengan alat (tools) dan teknik yang dibutuhkan dalam sistem sehingga hasil analisis dari sistem yang dikembangkan menghasilkan sistem yang strukturnya dapat didefinisikan dengan baik dan jelas.

Pada tahap ini juga digunakan notasi-notasi yang berlaku dalam mengimplementasikan sistem kerangkauntuk menggambarkan arus data sistem sehingga dapat membantu dalam proses komunikasi dengan pemakai. Kerangka digunakan untuk menggambarkan sistem baru yang akan dikembangkan secara logika tanpa terlebih dahulu mempertimbangkan lingkungan fisik di mana data tersebut diproses.

\section{Hasil dan Pembahasan}

Data yang dikumpulkan adalah data sekunder berupa transaksi penjualan barang dari Apotek Rafif Farma Medan. Setelah data sekunder diambil maka peneliti akan menentukan nilai Support minimum dan Confidence minimum berdasarkan data penjualan barang dari Apotek tersebut. 


\subsection{Analisis Data}

Proses pembentukan pola kombinasi itemsets dan pembuatan rules dimulai dari menganalisis data. Data yang digunakan adalah data transaksi penjualan obat, kemudian dilanjutkan dengan pembentukan pola kombinasi itemsets dan dari pola kombinasi itemsets tersebut terbentuk Association Rules.

1. Data transaksi penjualan

Data transaksi merupakan data yang diperoleh dari penjualan harian. Berikut ini merupakan dari data transaksi penjualan barang pada Apotek Rafif Farma Medan.

Tabel 4.1.Tabel Sekunder Data Penjualan Obat Apotek Rafif Farma Medan

\begin{tabular}{|c|c|c|c|c|}
\hline $\begin{array}{c}\text { Kode } \\
\text { Penjualan }\end{array}$ & Kode Barang & Nama Barang & Harga Barang & $\begin{array}{l}\text { Tanggal } \\
\text { Penjualan }\end{array}$ \\
\hline \multirow[t]{5}{*}{ PJ140103002 } & RF000007 & Betason- $\mathrm{N}$ & $\mathrm{Rp} \quad 11,000$ & $1 / 3 / 2014$ \\
\hline & RF000032 & Hemaviton & $\mathrm{Rp} \quad 6,000$ & $1 / 3 / 2014$ \\
\hline & RF000004 & Ampicilin & $\mathrm{Rp} \quad 5,000$ & $1 / 3 / 2014$ \\
\hline & RF000011 & Zestam & $\mathrm{Rp} \quad 12,000$ & $1 / 3 / 2014$ \\
\hline & RF000009 & Antangin Is & $\mathrm{Rp} \quad 1,500$ & $1 / 3 / 2014$ \\
\hline \multirow[t]{5}{*}{ PJ140103003 } & RF000066 & Visine & $\mathrm{Rp} \quad 2,000$ & $1 / 3 / 2014$ \\
\hline & RF000077 & Lapited & Rp $\quad 2,200$ & $1 / 3 / 2014$ \\
\hline & RF000044 & Caladine & $\mathrm{Rp} \quad 11,000$ & $1 / 3 / 2014$ \\
\hline & RF000078 & Kalpanax & $\mathrm{Rp} \quad 7,000$ & $1 / 3 / 2014$ \\
\hline & RF000050 & Menara 5 & $\mathrm{Rp} \quad 1,000$ & $1 / 3 / 2014$ \\
\hline \multirow[t]{2}{*}{ PJ140103004 } & RF000049 & Enervon-C & $\mathrm{Rp} \quad 4,000$ & $1 / 3 / 2014$ \\
\hline & RF000010 & Omeroxol & $\mathrm{RD} \quad 5,000$ & $1 / 3 / 2014$ \\
\hline \multirow[t]{2}{*}{$\begin{array}{c}\text { Eodi } \\
\text { Popiyulas }\end{array}$} & Fede Brong & Neme Broses & Herge Bsesng & 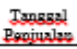 \\
\hline & RFOCO045 & Bropiss & $\mathrm{BR} \quad 2,500$ & 1/3/2014 \\
\hline \multirow[t]{5}{*}{ PJ140103002 } & RFOCOOOOT & Bessers-N & 䎽 $\quad 11,000$ & 1/3/2014 \\
\hline & $\mathrm{RF} O 00032$ & Hemaniton & BR $\quad 6,000$ & 1/3/2014 \\
\hline & RFO00004 & Anseicilin & BR. $\quad 5,000$ & $1 / 3 / 2014$ \\
\hline & RFOOOO11 & Zatam & BR. $\quad 12,000$ & 1/3/2014 \\
\hline & RFOCOOOO & dntrangin $\mathrm{Lk}$ & Bg $\quad 1,500$ & 1/3/2014 \\
\hline \multirow[t]{2}{*}{ PJ140103003 } & RPo00066 & Visine & BR $\quad 2,000$ & $1 / 3 / 2014$ \\
\hline & RFOCO0077 & Ispited & Bg $\quad 2,200$ & $1 / 3 / 2014$ \\
\hline \multirow[t]{3}{*}{$\perp$} & RPOCOOO44 & Glading & $\mathbb{B}_{R} \quad 11,000$ & 1/3/2014 \\
\hline & RFOCO078 & Yalemens & BR. $\quad 7,000$ & 1/3/2014 \\
\hline & RFocososo & 2ksurge 5 & $B_{R} \quad 1,000$ & 1/3/2014 \\
\hline \multirow[t]{5}{*}{ PJ140103004 } & RFOCOO49 & Fassesp-C & BR $\quad 4,000$ & 1/3/2014 \\
\hline & RFO00010 & Sessersol & BR $\quad 5,000$ & 1/3/2014 \\
\hline & RFOCOOHS & Prepish & BR $\quad 2,500$ & 1/3/2014 \\
\hline & RPOCOCOO3 & Deszessig. & $\mathbb{B}_{R} \quad 15,000$ & 1/3/2014 \\
\hline & RFOCOOT3 & didem Suri & BR $\quad 1,500$ & 1/3/2014 \\
\hline \multirow[t]{7}{*}{ PJ140103007 } & RFOCOO23 & Kerck & $B_{R} \quad 8,500$ & 1/3/2014 \\
\hline & RFOCOO69 & Alsobsel & BR $\quad 5,000$ & 1/3/2014 \\
\hline & RFO00065 & $\mathrm{B}_{3 \mathrm{O}}=\mathrm{m}$ & BR $\quad 3,000$ & 1/3/2014 \\
\hline & RFOCO076 & Xerciming & BR. $\quad 3,000$ & 1/3/2014 \\
\hline & RFOCOO67 & Sembantrie & BR $\quad 11,000$ & 1/3/2014 \\
\hline & RFOCO039 & Brosold & BR $\quad 5,000$ & 1/3/2014 \\
\hline & RFocooss & Cursums & 职 $\quad 13,000$ & 1/3/2014 \\
\hline \multirow[t]{2}{*}{ PJ140103010 } & RFOCOOOS & Hufacis & $B_{R} \quad 12,000$ & 1/3/2014 \\
\hline & RFOOOOOO & Astrangin If & Bg. $\quad 1,500$ & $1 / 3 / 2014$ \\
\hline
\end{tabular}

Data di atas adalah bentuk transaksi data penjualan (data obat keluar) real terdiri atas attribute Kode penjualan, Kode Barang, Nama Barang, Harga Barang dan Tanggal Penjualan.

\section{Penentuan Kandidat Pertama}

Bentuk data 1 item yang terdiri atas attribute item sebagai nama item jenis semua barang apotek yang ada di dalam transaksi, Support yaitu jumlah setiap item yang ada disemua transaksi, sedangkan Support (\%) adalah tabel real data yang ada di dalam transkasi, yang didapat dari jumlah item dibagi jumlah semua transaksi yang akan dianalisis di kali seratus persen.

Nilai Support masing-masing item dapat dihitung dengan cara sebagai berikut :

1. Nilai Support Adem Sari dapat dihitung dengan rumus : 


$$
\begin{aligned}
& \text { Support }=\frac{\text { Jumlah Adem Sari di seluruh transaksi }}{\text { Total transaksi }} \times 100 \% \\
& =\frac{10}{59} \times 100 \% \\
& =16,9 \%
\end{aligned}
$$

2. Nilai Support Albotil dapat dihitung dengan rumus :

$$
\begin{aligned}
& \text { Support }=\frac{\text { Jumlah Albotil di seluruh transaksi }}{\text { Total transaksi }} \times 100 \% \\
& =\frac{18}{59} \times 100 \% \\
& =30,5 \%
\end{aligned}
$$

3. Nilai Support Alkohol dapat dihitung dengan rumus :

$$
\begin{aligned}
& \text { Support }=\frac{\text { Jumlah Alkohol di seluruh transaksi }}{\text { Total transaksi }} \times 100 \% \\
& =\frac{31}{59} \times 100 \% \\
& =52,5 \%
\end{aligned}
$$

4. Nilai Support Ambeven dapat dihitung dengan rumus :

$$
\begin{aligned}
& \text { Support }=\frac{\text { Jumlah Ambeven di seluruh transaksi }}{\text { Total transaksi }} \times 100 \% \\
& =\frac{6}{59} \times 100 \% \\
& =10,2 \%
\end{aligned}
$$

Setelah melakukan perhitungan pencarian nilai Support pada seluruh item barang didapatkan nilai Support sebagai berikut :

$$
\text { yang terendah }
$$

Tabel 4.2 : Jenis Items Obat yang Memenuhi Support Minimal Setelah diurutkan

\begin{tabular}{|r|l|c|c|}
\hline No & Nama Barang & Support & Support \% \\
\hline 1 & Vitacimin & 15 & 25.4 \\
\hline 2 & Fresh Care & 16 & 27.1 \\
\hline 3 & Caladine & 17 & 28.8 \\
\hline 4 & Dexatamin & 17 & 28.8 \\
\hline 5 & Albotil & 18 & 30.5 \\
\hline 6 & Amoxilin & 19 & 32.2 \\
\hline 7 & Betadine & 26 & 44.1 \\
\hline 8 & Alkohol & 31 & 52.5 \\
\hline
\end{tabular}

\subsubsection{Analisa Pola Frekuensi Tinggi}

\subsubsection{Pembentukan Pola Kombinasi Dua Itemsets}

Pembentukan pola frekuensi dua itemsets, dibentuk dari items-items jenis obat yang memenuhi Support minimal yaitu dengan cara mengkombinasi semua items kedalam pola dua kombinasi, hasil pembentukan pola kombinasi dua itemsets yang dibentuk dari tabel 4 dengan rumus sebagai berikut :

1. Nilai Support Vitacimin dan Fresh Care dapat dihitung dengan rumus :

$$
\text { Support }=\frac{\text { Transaksi }(\text { Vitacimin, Fresh Care) }}{\text { Total Transaksi } 118} \times 100 \%
$$




$$
\begin{aligned}
& =\frac{14}{59} \times 100 \% \\
& =23.7 \%
\end{aligned}
$$

2. Nilai Support Vitacimin dan Alkohol dapat dihitung dengan rumus :

$$
\begin{aligned}
& \text { Support }=\frac{\text { Transaksi (Vitacimin dan Alkohol) }}{\text { Total Transaksi }} \times 100 \% \\
= & \frac{12}{59} \times 100 \% \\
= & 20.3 \%
\end{aligned}
$$

3. Nilai Support Amoxilin dan Alkohol dapat dihitung dengan rumus :

$$
\begin{aligned}
& \text { Support }=\frac{\text { Transaksi }(\text { Amoxilin, Alkohol })}{\text { Total Transaksi }} \times 100 \% \\
= & \frac{12}{59} \times 100 \% \\
= & 20.3 \%
\end{aligned}
$$

4. Nilai Support Betadine dan Alkohol dapat dihitung dengan rumus :

$$
\begin{aligned}
& \text { Support }=\frac{\text { Transaksi (Betadine dan Alkoho) }}{\text { Total Transaksi }} \times 100 \% \\
= & \frac{24}{59} \times 100 \% \\
= & 40.7 \%
\end{aligned}
$$

Setelah melakukan pencarian dan perhitungan nilai Support Kombinasi Dua Itemsets pada seluruh item barang didapatkan nilai seperti tabel 4.4 di bawah ini:

Tabel 4.5 : Pola Kombinasi Dua Itemsets

\begin{tabular}{|l|c|r|}
\hline \multicolumn{1}{|c|}{ Nama Barang } & Support & $\begin{array}{c}\text { Support } \\
\text { \% }\end{array}$ \\
\hline Vitacimin, Fresh Care & 14 & 23.7 \\
\hline Vitacimin, Caladine & 3 & 5.1 \\
\hline Vitacimin, Dexatamin & 5 & 8.5 \\
\hline Vitacimin, Albotil & 5 & 8.5 \\
\hline Vitacimin, Amoxilin & 7 & 11.9 \\
\hline Vitacimin, Betadine & 9 & 15.3 \\
\hline Vitacimin, Alkohol & 12 & 20.3 \\
\hline Fresh Care, Caladine & 4 & 6.8 \\
\hline Fresh Care, Dexatamin & 6 & 10.2 \\
\hline Fresh Care, Albotil & 5 & 8.5 \\
\hline Fresh Care, Amoxilin & 9 & 15.3 \\
\hline Fresh Care, Betadine & 9 & 15.3 \\
\hline Fresh Care, Alkohol & 11 & 18.6 \\
\hline Caladine, Dexatamin & 5 & 8.5 \\
\hline Caladine, Albotil & 8 & 13.6 \\
\hline Caladine, Amoxilin & 3 & 5.1 \\
\hline Caladine, Betadine & 8 & 13.6 \\
\hline Caladine, Alkohol & 8 & 13.6 \\
\hline
\end{tabular}




\begin{tabular}{|l|c|c|} 
Dexatamin, Albotil & 6 & 10.2 \\
\hline Dexatamin, Amoxilin & 10 & 16.9 \\
\hline Dexatamin, Betadin & 9 & 15.3 \\
\hline Dexatamin, Alkohol & 9 & 15.3 \\
\hline Albotil, Amoxilin & 7 & 11.9 \\
\hline Albotil, Betadine & 7 & 11.9 \\
\hline Albotil, Alkohol & 11 & 18.6 \\
\hline Amoxilin, Betadin & 8 & 13.6 \\
\hline Amoxilin, Alkohol & 12 & 20.3 \\
\hline Betadin, Alkohol & 24 & 40.7 \\
\hline
\end{tabular}

Data di atas merupakan calon kombinasi dua item yang merupakan hasil dari semua kombinasi semua jenis item.

Tabel 4.6 : Daftar Pola kombinasi dua items yang memenuhi Support minimal

\begin{tabular}{|l|c|c|}
\hline \multicolumn{1}{|c|}{ Nama Barang } & Support & $\begin{array}{c}\text { Support } \\
\%\end{array}$ \\
\hline Vitacimin, Fresh Care & 14 & 23.7 \\
\hline Vitacimin, Alkohol & 12 & 20.3 \\
\hline Amoxilin, Alkohol & 12 & 20.3 \\
\hline Betadin, Alkohol & 24 & 40.7 \\
\hline
\end{tabular}

Dari hasil data di atas, pembentukan dua itemsets berhenti sampai disini karena tidak memungkinkan lagi untuk dibentuk kombinasi itemsets berikut, dengan demikian kombinasi dua itemsets yang terpilih dengan Support yang telah ditentukan, terlihat data kombinasi yaitu jenis Vitacimin dan Fresh Care, Vitacimin dan Alkohol, Amoxilin dan Alkohol, Betadine dan Alkohol. Betadin dan Alkohol menandakan bahwa kombinasi dua item data tersebut paling banyak di dalam transaksi.

\subsubsection{Pembentukan Pola Aturan Asosiasi}

Setelah semua pola frekuensi tinggi ditemukan, baru la dicari aturan asosiasi yang memenuhi syarat minimum untuk Confidence dengan menghitung Confidence aturan asosiati A ke B. Nilai Confidence dari aturan A ke B.

Proses mencari jumlah kombinasi dan kuatnya hubungan antara satu item dengan item yang lain dalam satu kombinasi disebut metode Association Rule. Pembentukan Association Rule adalah menganalisis pola frekuensi tinggi, tahap ini mencari kombinasi yang memenuhi syarat minimum dari Support dalam database., Pembentukan aturan Association Rule, dengan mencari nilai Confidence. Di mana Support adalah jumlah dari kombinasi antara suatu item dengan item yang lain sedangankan Confidence adalah nilai yang mendefinisikan kuat tidaknya hubungan antara item-item tersebut.

Dari tabel 4.6 yaitu tabel pola kombinasi dua item, dapat dicari nilai Confidence dengan rumus sebagai berikut :

$$
\begin{aligned}
\text { Confidence } & =\frac{\text { Transaksi Vitacimin dan Fresh Care }}{\text { Transaksi Vitacimin }} \times 100 \\
& =\frac{14}{15} \times 100 \% \\
& =93.333
\end{aligned}
$$

Sehingga hasil aturan asosiasi ditemukan, seperti tabel 4.6.

Tabel 4.7 Aturan Asosiasi

\begin{tabular}{|l|l|r|}
\hline \multicolumn{1}{|c|}{ Nama Barang } & \multicolumn{2}{c|}{ Confidence } \\
\hline Vitacimin, Fresh Care & $14 / 15$ & 93.3 \\
\hline Vitacimin, Alkohol & $12 / 15$ & 80.0 \\
\hline Amoxilin, Alkohol & $12 / 19$ & 63.2 \\
\hline
\end{tabular}




\begin{tabular}{|l|l|l|} 
Betadin, Alkohol & $24 / 26$ & 92.3 \\
\hline
\end{tabular}

Dari tabel 4.6 yaitu tabel pola kombinasi dua item, dapat dilihat besarnya nilai Support dan Confidence dari calon aturan asosiasi seperti tampak pada tabel 4.7 .

Setelah semua pola frekuensi tinggi ditemukan, baru dicari Association Rules yang memenuhi syarat minimum Confidence, dengan menghitung Confidence aturan asosiasi A ke B.

Tabel 4.8 : Daftar Calon Aturan Asosiasi

\begin{tabular}{|l|c|c|c|}
\hline \multicolumn{1}{|c|}{ Nama Barang } & Support & \multicolumn{2}{c|}{ Confidence } \\
\hline $\begin{array}{l}\text { Jika membeli Vitacimin maka akan membeli } \\
\text { Fresh Care }\end{array}$ & 23.7 & $14 / 15$ & 93.3 \\
\hline $\begin{array}{l}\text { Jika membeli Fresh Care maka akan membeli } \\
\text { Vitacimin }\end{array}$ & 23.7 & $14 / 16$ & 87.5 \\
\hline $\begin{array}{l}\text { Jika membeli Vitacimin maka akan membeli } \\
\text { Alkohol }\end{array}$ & 20.3 & $12 / 15$ & 80.0 \\
\hline $\begin{array}{l}\text { Jika membeli Alkohol maka akan membeli } \\
\text { Vitacimin }\end{array}$ & 20.3 & $12 / 31$ & 38.7 \\
\hline $\begin{array}{l}\text { Jika membeli Amoxilin maka akan membeli } \\
\text { Alkohol }\end{array}$ & 20.3 & $12 / 19$ & 63.2 \\
\hline $\begin{array}{l}\text { Jika membeli Alkohol maka akan membeli } \\
\text { Amoxilin }\end{array}$ & 20.3 & $12 / 31$ & 38.7 \\
\hline $\begin{array}{l}\text { Jika membeli Betadine maka akan membeli } \\
\text { Alkohol }\end{array}$ & 40.7 & $24 / 26$ & 92.3 \\
\hline Jika membeli Alkohol maka akan Betadine & 40.7 & $24 / 31$ & 77.4 \\
\hline
\end{tabular}

Untuk melihat kuat tidaknya aturan asosiasi adalah membandingkannya dengan nilai Benchmark, di mana diasumsikan kejadian item dari Consequent dalam suatu transaksi adalah independent dengan kejadian dari antecedent dari suatu aturan asosiasi. Nilai estimasi dari Confidence Benchmark dihitung dari data suatu aturan dengan ketentuan sebagai berikut :

1. Mencari Lift Vitacimin :

$$
\begin{aligned}
& \text { Confidence_benchmark }=\frac{\text { Jumlah transaksi Vitacimin }}{\text { Jumlah transaksi }} \times 100 \\
& \text { Confidence_benchmark }=\frac{15}{59} \times 100 \\
& =25,423 \\
& \text { Lift Vitacimin }=\frac{\text { Confidence Vitacimin (Consequent) }}{\text { Confidenc } e_{\text {benchmark }} \text { Alkohol }} \times 100 \\
& =\frac{87,500}{25,423} \times 100 \\
& =3,441765
\end{aligned}
$$

2. Mencari Lift Fresh Care:

$$
\begin{aligned}
& \text { Confidence_benchmark }=\frac{\text { Jumlah transaksi Fresh Care }}{\text { Jumlah } \text { transaksi }} \times 100 \\
& \text { Confidence_benchmark }=\frac{16}{59} \times 100 \\
& =27.11864 \\
& \text { Lift Betadine }=\frac{\text { Confidence Fresh Care }_{(\text {Consequent })}}{\text { Confidence }_{\text {benchmark }} \text { Betadine }} \times 100
\end{aligned}
$$




$$
\begin{aligned}
& =\frac{93.333}{27.11864} \times 100 \\
& =3,44
\end{aligned}
$$

Jika nilai lift rasio lebih besar dari pada 1 menunjukkan adanya manfaat dari aturan tersebut. Lebih tinggi nilai lift rasio, lebih besar kekuatan asosiasi. Dari tabel yaitu tabel pola kombinasi dua itemsets, dapat dilihat besarnya nilai Support dan Confidence dari calon Association Rules seperti tampak pada tabel 4.8 berikut ini:

Tabel 4.9 : Aturan Asosiasi

\begin{tabular}{|l|c|c|c|}
\hline \multicolumn{1}{|c|}{ Nama Barang } & Lift & Support & Confidence \\
\hline Jika membeli Vitacimin maka akan membeli Fresh Care & 3.441765 & 23.7 & 93.3 \\
\hline Jika membeli Fresh Care maka akan membeli Vitacimin & 3.441765 & 23.7 & 87.5 \\
\hline Jika membeli Vitacimin maka akan membeli Alkohol & 1.79901 & 20.3 & 80 \\
\hline Jika membeli Alkohol maka akan membeli Vitacimin & 1.79901 & 20.3 & 38.7 \\
\hline Jika membeli Amoxilin maka akan membeli Alkohol & 1.18166 & 20.3 & 63.2 \\
\hline Jika membeli Alkohol maka akan membeli Amoxilin & 1.18166 & 20.3 & 38.7 \\
\hline Jika membeli Betadine maka akan membeli Alkohol & 1.79901 & 40.7 & 92.3 \\
\hline Jika membeli Alkohol maka akan Betadine & 1.79901 & 40.7 & 77.4 \\
\hline
\end{tabular}

Dari tabel 4.8 di atas, maka hasil Association Rule yang dihasilkan adalah :

1. Jika membeli Vitacimin, juga akan membeli Fresh Care, maka nilai Supportnya adalah $23,7 \%$ dan nilai Confidennya adalah 93,333

2. Item A dan B dibeli bersamaan sebesar 23,7\% dari data keseluruhan data transaksi yang dianalisis dan 93,333\% dari semua konsumen yang membeli Item A juga membeli item B

3. Jika membeli Fresh Care, juga akan membeli Vitacimin, maka nilai Supportnya adalah 23,7\% dan nilai Confidennya adalah 87,5

4. Item B dan A dibeli bersamaan sebesar 23,7\% dari data keseluruhan data transaksi yang dianalisis dan $87,5 \%$ dari semua konsumen yang membeli item B juga membeli item A.

5. Jika membeli Vitacimin, juga akan membeli Alkohol, maka nilai Supportnya adalah 20,3\% dan nilai Confidennya adalah $80 \%$

6. Item A dan B dibeli bersamaan sebesar 20,3\% dari data keseluruhan data transaksi yang dianalisis dan $80 \%$ dari semua konsumen yang membeli Item A juga membeli item B

7. Jika membeli Alkohol, juga akan membeli Vitacimin, maka nilai Supportnya adalah 20,3\% dan nilai Confidennya adalah $38.7 \%$

8. Item $\mathrm{B}$ dan A dibeli bersamaan sebesar 20,3\% dari data keseluruhan data transaksi yang dianalisis dan $38.7 \%$ dari semua konsumen yang membeli item $\mathrm{B}$ juga membeli item A.

9. Jika membeli Amoxilin, juga akan membeli Alkohol, maka nilai Supportnya adalah 20,3\% dan nilai Confidennya adalah $63.2 \%$

10. Item A dan B dibeli bersamaan sebesar 20,3\% dari data keseluruhan data transaksi yang dianalisis dan $63.2 \%$ dari semua konsumen yang membeli Item A juga membeli item B

11. Jika membeli Alkohol, juga akan membeli Amoxilin, maka nilai Supportnya adalah 20,3\% dan nilai Confidennya adalah $38.7 \%$

12. Item B dan A dibeli bersamaan sebesar 20,3\% dari data keseluruhan data transaksi yang dianalisis dan $38.7 \%$ dari semua konsumen yang membeli item B juga membeli item A.

13. Jika membeli Betadine, juga akan membeli Alkohol, maka nilai Supportnya adalah 40,7\% dan nilai Confidennya adalah $92.3 \%$

14. Item A dan B dibeli bersamaan sebesar 40,7\% dari data keseluruhan data transaksi yang dianalisis dan 92.3\% dari semua konsumen yang membeli Item A juga membeli item B

15. Jika membeli Alkohol, juga akan membeli Betadien, maka nilai Supportnya adalah 40,7\% dan nilai Confidennya adalah $77.4 \%$

16. Item B dan A dibeli bersamaan sebesar 40,7\% dari data keseluruhan data transaksi yang dianalisis dan 77.4\% dari semua konsumen yang membeli item $\mathrm{B}$ juga membeli item A. 


\section{KESIMPULAN}

Berdasarkan penelitian dan pembahasan yang dilakukan, maka dapat disimpulkan beberapa hal sebagai berikut :

1. Data Mining adalah suatu proses untuk menemukan pola-pola di dalam data, di mana proses penemuan tersebut dilakukan secara otomatis atau semi otomatis dan pola yang ditemukan harus bermanfaat sebagai ilmu pengetahuan yang baru dan informasi penting dari data penjualan Apotek Rafif Farma.

2. Penerapan Algoritma Apriori berpedoman pada perhitungan nilai Support dan Confidence. Dalam proses menghitung nilai Support dan Confidence akan lebih sulit, jika data yang ingin diolah dalam jumlah besar.

\section{DAFTAR PUSTAKA}

[1] Vipul Mangla, Chandni Sarda, Sarthak Madra. (2013). "Improving the efficiency of Apriori Algorithm in Data Mining". International Journal of Engineering and Innovative Technology (IJEIT) Volume 3, Issue 3.

[2] Mohammed Abdul Khaleel1, Sateesh Kumar Pradhan.(2013). “Finding Locally Frequent Diseases Using Modified Apriori Algorithm". International Journal of Advanced Research in Computer and Communication Engineering. Vol. 2. Issue 10.

[3] Jaishree Singh, Hari Ram, Dr. J.S. Sodhi. (2013). "Improving Efficiency of Apriori Algorithm Using Transaction Reduction". International Journal of Scientific and Research Publications.Volume 3. Issue 1.

[4] Fadlina. (2014). "Data Mining Untuk Analisa Tingkat Kejahatan Jalanan Dengan Algoritma Association Rule Metode Apriori". Informasi dan Teknologi Ilmiah. Volume : III.

[5] Angga Ginanjar Mabrur, Riani Lubis. (2012), " Penerapan Data Mining Untuk Memprediksi Kriteria Nasabah Kredit". Jurnal Komputer dan Informatika (KOMPUTA). 53 Edisi. I. Volume. 1.

[6] Gunadi Widi Nurcahyo, "Penerapan Data Mining dengan Algoritma Apriori untuk Mendukung Strategi Promosi Pendidikan". Universitas Putra Indonesia YPTK.

[7] Eka Novita Sari. (2013), " Analisa Algoritma Apriori Untuk Menentukan Merek Pakaian Yang Paling Diminati Pada Mode Fashion Group Medan". Pelita Informatika Budi Darma. Volume : IV. Nomor: 3.

[8] Kennedi Tampubolon, Hoga Saragih, Bobby Reza.(2013), "Implementasi Data Mining Algoritma Apriori Pada Sistem Persediaan Alat-Alat Kesehatan". Majalah Ilmiah Informasi dan Teknologi Ilmiah. Volume : I.

[9] Dian Wirdasari, Ahmad Calam. "Penerapan Data Mining Untuk Mengolah Data Penempatan Buku Di Perpustakaan SMK TI PAB 7 Lubuk Pakam Dengan Metode Association Rule". Program Studi Ilmu Komputer, Universtias Sumatera Utara.

[10] Dana Sulistiyo Kusumo, Moch. Arief Bijaksana, Dhinta Darmantoro. (2010), "Data Mining Dengan Algoritma Apriori Pada RDBMS Oracle". Jurusan Teknik Informatika Sekolah Tinggi Teknologi Telkom.

[11] Dewi Kartika Pane. (2012), "Implementasi Data Mining Pada Penjualan Produk Elektronik Dengan Algoritma Apriori”. Pelita Informatika Budi Darma. Volume : IV. Nomor: 3.

[12] Goldie Gunadi, Dana Indra Sensuse. (2012), "Penerapan Metode Data Mining Market Basket Analysis Terhadap Data Penjualan Produk Buku Dengan Menggunakan Algoritma Apriori Dan Frequent Pattern Growth (FP-GROWTH) : Studi Kasus Percetakan PT. GRAMEDIA". Jurnal Telematika M.Kom Vol.4 No.1. 